nekaterim kritičnim pripombam je torej pričujoča izdaja velik prispevek $\mathrm{k}$ našemu uvidu v Cicerona, zaradi svoje mnogostranskosti pa tudi $\mathrm{v}$ antično kulturo sploh.

Nada Grošelj

\title{
PORTRET FRANCA OMERZE ${ }^{1}$
}

\author{
Benjamin BEVC
}

\section{Omerzova mladost in šolanje}

Franc Omerza se je rodil 28. marca 1885 v Župeči vasi na Dolenjskem v družini z osmimi otroki. Pri desetih letih je začel obiskovati ljudsko šolo dvorazrednico v Cerkljah ob Krki. Njegov oče, po poklicu sicer kmet in kovač, je bil zelo napreden in ga je po končani ljudski šoli vpisal na gimnazijo v Novem mestu. Ker gimnazija ni imela internata za oddaljene dijake, je Omerza vseh osem let šolanja živel pri dijaških gospodinjah. Bil je zelo marljiv dijak in je v tretjem letniku začel prejemati štipendijo Paula Waranna, kije letno znašala 194 kron. Maturiral je 27. junija 1905 iz enajstih predmetov, pri grščini in latinščini - kasnejših študijskih predmetih - je bil lobenswert (posebej pohvaljen).

Jeseni istega leta je vstopil v ljubljansko bogoslovje. Že kot bogoslovec je leta $1908 \mathrm{ob}$ 1500-letnici smrti svetega Janeza Zlatousta v priložnostnem zborniku objavil daljšo pesem v latinščini z naslovom Joannes Chrysostomus, Lux ex Oriente. Kasneje je objavil še več priložnostnih pesmi. V njih se lepo kaže Omerzova osebnost: pesmi so preproste, večinoma $z$ religiozno tematiko in pisane $v$ latinščini.

V duhovnika je bil posvečen 12.julija 1908. Posvetil ga je takratni ljubljanski knezoškof Anton Bonaventura Jeglič. Po posvečenju je bil leto dni semeniški duhovnik, nato pa ga je Jeglič namenil za profesorja na Škofijski klasični gimnaziji v Šentvidu nad Ljubljano in ga poslal na Dunaj študirat klasično filologijo in slovenščino. Zahtevni študij je dokončal že v treh letih.

1 Pričujoči članek je predelana verzija raziskovalne naloge, ki je nastala v minulem šolskem letu na Škofijski klasični gimnaziji kot splet avtorjevega osebnega navdušenja za klasično filologijo in zanimanja za zgodovino prve slovenske gimnazije. V njej sem želel predstaviti Franca Omerzo, profesorja latinščine in grščine, pomembnega, a malo poznanega prevajalca antične književnosti ter režiserja, ki je prvi na Slovenskem uprizoril Ajshilovo Orestejo in Sofoklejevega Kralja Ojdipa. Glavni del raziskovanja sem posvetil prebiranju Omerzovih objavljenih prevodov in iskanju neobjavljenih. Sprejem njegovega prevajalskega dela sem skušal osvetliti s sočasnimi kritikami. Veliko sem o Omerzovih prevodih izvedel tudi iz pogovorov z dr. Kajetanom Gantarjem, prof. Janko Modrom in Gorazdom Kocijančičem, o Omerzi kot profesorju pa iz pogovorov z dr. Jožo Mahničem in dr. Stanetom Gabrovcem. Vsem imenovanim se iskreno zahvaljujem za njihov čas in potrpežljivost. 


\section{Profesor na Škofijski klasični gimnaziji}

Septembra leta 1913 je prišel v Zavod sv. Stanislava, kjer je živel in deloval vse do svoje smrti leta 1940. Na Škofijski klasični gimnaziji, ki je delovala v okviru zavoda, je poučeval latinščino, grščino in slovenščino. Kmalu po prihodu v zavod je začel objavljati svoje prve prevode, ki jih bom podrobneje predstavil v naslednjem poglavju. Večino prevodov je objavil v Mentorju, dijaškem listu, ki ga je leta 1908 začel izdajati Zavod sv. Stanislava. V letih po prvi svetovni vojni je Omerza tudi sam postal urednik Mentorja. Uredil je dvanajsti in trinajsti letnik, žal pa je nato Mentor iz finančnih razlogov prenehal izhajati.

Omerza je sodeloval tudi pri pisanju latinskih slovnic in vadnic, $\mathrm{ki}$ so jih $\mathrm{v}$ letih pred drugo svetovno vojno spisali zavodski profesorji Franc Belec, Frančišek Jerè, Ivan Samsa ter Alojzij Strupi. Kot soavtor je naveden pri Latinski slounici in vadnici za 1. razred klasične in 5. razred realne gimnazije ter pri Latinski slovnici in vadnici za 3. in 4. razred klasične in 7. razred realne gimnazije.

Poučevanje na gimnaziji ter intenzivno prevajalsko delo - velikokrat je prevajal dolgo v noč - med prvo svetovno vojno in v prvih letih po njej ga je močno izčrpalo, zato se je po letu 1923 obseg dela močno zmanjšal. Kasneje je bil večkrat bolan in je bil daljši čas na bolniškem dopustu. Jeseni leta 1940 je stopil v pokoj, ki pa ga ni dolgo užival. 17. decembra 1940 je umrl v starosti petinpetdeset let. Čez dva dni so ga pokopali v zavodsko grobnico na šentviškem pokopališču. Všolski kroniki je nekoliko hladno zapisano: »Dne 19. decembra je bil ob 8. uri pogreb prof. Fr. Omerza; udeležili so se ga vsi učenci s profesorji; 4. in 5. uro pa je bil zopet pouk.«²

\section{Prevajalec}

Zaradi svojega raznolikega in obsežnega prevajalskega opusa je Franc Omerza najpomembnejši slovenski prevajalec antične književnosti z začetka dvajsetega stoletja. Skupaj z Jovanom Veselom Koseskim, Ivanom Božičem, Matijo Valjavcem, Valentinom Kermaunerjem in Antonom Doklerjem sodi v prehodno generacijo klasičnih filologov, ki je pripravljala in napovedovala zrelo dobo prevajanja antične književnosti v slovenščino.

Kajje Omerzo nagnilo, da je -večinoma brez plačila-opravil tolikšno prevajalsko delo? Temeljna razloga sta dva. Prvi je ljubezen do antike in veselje do prevajanja; že kot bogoslovec, ko verjetno sploh še ni vedel, da bo študiral klasično filologijo in postal profesor na gimnaziji, je prevajal Filokteta. Drugi razlog pa je njegov položaj profesorja latinščine in grščine na tedaj edini slovenski gimnaziji. Ker je bilo prevodov tedaj še zelo malo, se je kot klasični filolog čutil posebej poklicanega, da najpomembnejša dela antične književnosti prevede v slovenščino.

Omerzovo prevajalsko delo lahko razdelimo v dve obdobji: zgodnje in zrelo.

2 Šolska kronika Škofijske klasične gimnazije za obdobje 1932-19141. Nadškofijski arhiv Ljubljana, mape Zavoda sv. Stanislava v Šentvidu, fasc. 3. 
Meja med njima je okoli leta 1923, ko je bil objavljen njegov zadnji prevod iz poganske antike, Ajshilova tragedija Maščevanje.

V zgodnjem prevajalskem obdobju je prevajal predvsem grško književnost, v manjši meri pa tudi rimsko. Med najpomembnejšimi prevodi iz tega obdobja sta Homerjeva epa Iliada in Odiseja, Sofoklovi tragediji Filoktet in Kralj Ojdip ter Ajshilova Oresteja. Pod vtisom strahot prve svetovne vojne je prevedel Aristofanovo komedijo Mir in odlomek iz Tukididove Peloponeške vojne. Prevajal pa je tudi rimsko poezijo: Horacijeve ode, Juvenalove in Horacijeve satire ter Marcialove in Katulove epigrame.

Njegove zgodnje prevode je močno zaznamovala mladost: prvi prevod je objavil pri osemindvajsetih letih, čez deset let zadnjega. Zaradi hitrega razvoja slovenskega jezika $v$ začetku dvajsetega stoletja, verjetno pa tudi zaradi osebne zaprtosti, predvsem njegovi zgodnji prevodi ne dajejo vtisa živosti. K temu je veliko pripomoglo včasih tudi pretirano spoštovanje do izvirnika, zlasti metrična zvestoba in pomenska dobesednost. Vse to kaže na vpliv nemške filološke šole, katere najpomembnejši predstavnik je bil v tistem času Ulrich Wilamowitz-Moellendorff. ${ }^{3}$

Naj se na kratko posebej ustavim pri metrumu. ${ }^{4}$ Omerza je sledil tedaj že uveljavljenemu običaju posnemanja antičnih kvantitativnih oblik z akcentuacijskim ritmom. V tragedijah je Omerza dialoge prevajal akcentuacijski različici jambskega trimetra. Ta zahteva naglas na zadnjem zlogu v verzu, to pa pogosto učinkuje trdo in monotono. Številni verzi v Omerzovem prevodu so zato okorni in so težko razumljivi; na primer prvi verz Sofoklovega Filoktela:

Obrežje tole Lemna je otoka kraj. ${ }^{5}$

$\mathrm{U}-\mathrm{U}-\mathrm{U}-\mathrm{U}-\mathrm{U}-\mathrm{U}-$

Še bolj nenavadno pa zvenijo prevodi zborovskih pesmi, kajti tudi v teh je skušal posnemati zapletene grške metrične obrazce. Za ponazoritev sem začetku zborovske pesmi iz Filokteta v Omerzovem prevodu dodal metrično shemo. Ta se $v$ resnici zelo ujema $\mathrm{z}$ originalno. ${ }^{6}$

Seveda videl nisem, praviti sem čul,

U-U-U-U-UUU-

ker se je bližal postelji Zevsovi

-UU-U-UU-UU

3 Prim. Kastelic, 1944, str. 4.

4 Na Omerzovo zanimanje za metriko lepo kaže zanimiv članek Prešernova »Nezakonska mati«, ki ga je Omerza leta 1916 objavil v Domu in svetu (Dom in svet 29 (1916), str. 217-219, str. 278-279). V njem je s prikazom metričnih oblik več starogrških in Prešernovih pesmi skušal pokazati, da Prešeren ni študiral »stare metrike samo iz metričnih knjig, ampak da je imel razen latinskih klasikov tudi grške lirike kot vzor pred seboj.«

5 Mentor, 1913/1914, str. 25.

6 Metrična shemaizvirnika:U-U-U-U-U-U-/-UU---UU-UU/U-UU-UU-UU-UU / --U-U--. 
Iksion, pripel na kolo je vrteče ga

-UUU-UU-UU-UU

sin Kronov velemožni. ${ }^{7}$

$--\mathrm{UUU}-\mathrm{U}$

Tradicijo posnemanja izvirnih metričnih oblik grške dramatike je pri nas prekinil šele Anton Sovrè, ki je leta 1922 v zborskih spevih Kralja Ojdipa uporabil prosti verz. Tako je bil svobodnejši pri izbiri besed in njihovem zaporedju. Njegovi prevodi so zato lažje razumljivi, kar lepo kaže odlomek iz Filokteta:

Slišal sem o njem, videl ga nisem,

Iksiona, ki se približal nekdaj

je Zeusa postelji;

pa ujel in privezal na urno kolo

je vsemogočni ga Kronov sin. ${ }^{8}$

Gantarjev prevod odlomek podaja najasnjeje:

Slišal sem zgodbo - videl je nisem -,

kako je Iksiona, ki se nekoč

približal je Zevsovi postelji,

Kronov sin vsegamogočni

zvezal na naglo vrteče kolo. ${ }^{9}$

Zaradi prej omenjenih dejavnikov (mladost, hiter razvoj slovenščine, pretirana zvestoba izvirniku) so Omerzovi zgodnji prevodi zelo hitro zastarali. Ker so večinoma izšli le v Mentorju ter Domu in svetu, ne pa tudi v knjižni obliki, niso imeli večjega odmeva v slovenski kulturni javnosti. Tudi zato so mnogi kasnejši prevodi, na primer Platona, ostali v rokopisu.

Kot prevajalec je Omerza zorel in se izpopolnjeval. V zrelem prevajalskem obdobju je večinoma prevajal igre, ki so jih dijaki igrali pri dramskem krožku $\mathrm{v}$ zavodu, in spise cerkvenih očetov. Prevodi iger so ostali v rokopisu in se niso ohranili, od prevodov cerkvenih očetov pa so nam v knjižni obliki ostali Spisi apostolskih očetov in Svetega Janeza Krizostoma izbrani spisi. Ti prevodi so boljši, zrelejši, sproščenejši.

\section{Iliada in Odiseja}

Najobsežnejši Omerzov prevod je prevod Homerjeve Iliade. Pred njim so jo slovenili že mnogi, a večinoma so to bili le fragmenti. Omerza pa se je lotil

7 Mentor, 1913/1914, str. 72.

8 Sofokles, Kralj Oidipus - Oidipus v Kolonu - Antigona - Filoktetes. Prevedel A. Sovrè. Ljubljana 1962.

9 Sofokles: Ajant-Trahinke-Filoktet. Prevedla K. Gantar (Ajant, Filoktet) in B. Senegačnik (Trahinke). Maribor, 2000. 
prevoda celotne Iliade in jo v nekaj letih tudi prevedel. Zanimivo je, da je v svojem prevodu namenoma izpustil nekatere verze, ker po njegovem mnenju niso sodili v Mentor, kjer je objavil večino prevoda. Objavljati ga je začel leta 1914 in do leta 1918 objavil dvanajst spevov. Mentor nato dve leti zaradi pomanjkanja sredstev ni izhajal. Ko pa se je leta 1921 obnovil, je Omerza objavil še trinajsti in začetek štirinajstega speva. Sredi leta 1923 je Zavod sv. Stanislava zaradi finančnih težav dokončno prenehal izdajati Mentorja in tako so prenehali izhajati tudi Omerzovi prevodi. Prvih šest spevov Iliade je kot ponatis iz Mentorja v skromni knjižici izšlo leta 1916, naslednjih pet pa leta 1919.

Da je Omerza res prevedel celotno Iliado in jo tudi želel objaviti, kaže dopisnica s poštnim žigom 1. marca 1920, ki jo je Omerza poslal uredniku Doma in sveta dr. Francu Steletu. V njej je zapisal: ${ }^{10}$

\section{"Dragi g. urednik!}

Če moreš kaj porabiti za Dom in svet, bi imel na razpolago - da pripomorem kaj po svojih močeh - sledeče prestave: Marcialovih epigramov ok. 400 (nekaj jih je že objavljenih v Mentorju); izbor iz Horatijevih in Juvenalovih satir (3 je že prinesel DS); Ajshilovo Orestijo, ki je pričela izhajati v Mentorju, pa je sedaj prenehal izhajati; Homer, Iliada XIII.-XXIV., Odiseja I-III.

Če Ti morem s tem kaj postreči, sem na razpolago.

Pozdrav!

Fr. Omerza«

Danes ni več mogoče ugotoviti, zakaj Dom in svet teh prevodov ni objavil. Verjetno je na to vplivalo mnenje nekaterih vodilnih slovenskih kulturnikov, ki so - kot bomo kmalu lahko videli - menili, da Omerzovi prevodi še niso dovolj dobri.

In kako zveni začetek Iliadev Omerzovem prevodu?

Srd mi opevaj, boginja Peléjeviča, Ahiléja, poln pogube, ki bóli Ahajcem nebroj je prinésel, močnih pa duš je nešteto hrabrih u boju junakov vrgel u Hades, a psom kot plen je izročil telesa, pticam kot slastno gostijo - vršili so se sklepi Zevsa ... ${ }^{11}$

Za primerjavo dodajam še tri druge prevode teh Homerjevih heksametrov. Jovan Vesel je začetne verze Iliade prevajal takole:

Boginja! serd mi zapoj Ahila junaka Pelida, ljuto razkačen ki zmot Ahajcam obilo nakloni, mnogo navdihnjenih duš prežene v temoto Plutona, trupe pa žretju zverin in tičev obnebja razpostre.

${ }^{10}$ Prim. tudi pričevanje I. Samse, spodaj, str. * in op. 19.

"Mentor, 1913/1914, str. 187. 
Tako dopolni se sklep Kronida ... ${ }^{12}$

Prevajalec, pisatelj in literarni zgodovinar Jože Debevec je v kritiki Omerzovega prevoda Iliade želel, da bi bili prvi verzi prevedeni odločneje. Sam bi prevedel:

Jezo mi, božica, poj Pelejevíča Ahila, ki, pogubna, nebroj je žali Ahajcem zadala, mnogih junakov u Had je duše poslala pogumne, trupla pa njihova v plen pripravila pasjim je žrelom in ujedam u jed - zgodila se Zevsu je volja - ...13

Seveda pa je najslovesnejši Anton Sovrè:

Pesem, boginja, zapoj, o jezi Pelida Ahila, Srdu pogubnem, ki silo gorja prizadel je Ahajcem:

Množico duš močnih upotil je v Hadove dvore, Duš junakov, a trupla pesòm prepustil je v žrtje, Pticam ujedam za plen: tako sklep Zeusov je tekel. ${ }^{14}$

Ob knjižni izdaji prvih šestih spevov lliade so v več revijah izšle vsebinsko zelo različne kritike prevoda. Joža Glonar v Ljubljanskem zvonu ter Aleš Ušeničnik v Času sta tako v svojih kritikah spregovorila predvsem o heksametru in prevajanju heksametra v slovenščino.

Teorijo slovenskega heksametra sta v 19. stoletju utemeljila Josip Stritar in Fran Levec. ${ }^{15}$ Osnova heksametra je daktil, ki ga lahko skoraj vedno nadomesti spondej. Toda ker so spondeji v slovenščini redki ali pa zelo slabi, kot na primer v besedi potok, je Stritar iznašel umetne, ponarejene spondeje. Prvo polovico spondeja naj bi predstavljal naglašen zlog, drugo polovico pa enozložna beseda ali pa prvi, lahko tudi nenaglašeni zlog druge besede. Vverzu Grob se za grobom vrsti z visoko travo zarastel je ponarejeni spondej v tretji stopici: sti - vi. Po Stritarjevem mnenju je slovenskemu heksametru treba dodati tudi zarezo, saj je heksameter brez zareze predolg, da bi ga mogli brati brez odmora. Stritar in Levec zahtevata vedno moško zarezo, saj je le-ta dovolj krepka. Ženska zareza po njunem mnenju slovenščini ne ugaja. V Stritarjevi pesmi Na Jenkovem grobu je v verzu $V$ zemlji domači ležiš, | predragi ti zemlji slovenski moška zareza, če pa verz preoblikujemo, dobimo žensko zarezo: Vzemlji počivaš domači, | predragi ti zemlji slovenski.

Joža Glonar je v svoji kritiki Omerzi očital nepoznavanje predhodnih prevodov in teorije slovenskega heksametra. Glonar je med drugim zapisal: »Skoro 4000 heksametrov smo dobili od njega, toda ti heksametri so brez vsakega homerskega

${ }^{19}$ Jovan Vesel Koseski: Razne dela pesniške in igrokazne, Ljubljana 1870, str. 222-302.

${ }^{13}$ Debevec, 1917, str. 183.

${ }^{14}$ Homer: Iliada. Prevedel A. Sovrè. Ljubljana, 1965.

${ }^{15}$ Teorijo povzemam po članku Aleša Ušeničnika v reviji Čas 10 (1917), str. 230-235. 
poleta, brez vsake gibčnosti in plastike. Prelagatelj čuti sam, zato opravičuje v predgovoru prve štiri speve, ki pa niso nič slabše zgrajeni od ostalih dveh. Njegov prevod in pa njegove besede o Stritarju in Koseskem v predgovoru so dokaz, da pozna tehniko našega heksametra in njega probleme vse premalo. ${ }^{16}$

Ušeničnikova kritika je tehtnejša, sajje v njej shematsko prikazal Omerzovo rabo heksametra. Zapisal je, da je Omerza predvsem v prvih štirih spevih namesto spondejev uporabil troheje in tako ti verzi šepajo. Kot primer takšnega verza navaja: Pravi in koj odhiti skozi vrata Hektor blešččci. Glede zareze pa je Ušeničnik pravi, da naj bi Omerza številne verze prevedel z moško zarezo, da pa je $\mathrm{v}$ prvih spevih več verzov z žensko glavno zarezo na tretji stopici, kjer je hkrati namesto spondeja trohej. Tako heksameter izgubi celoto in se razdeli na dve zelo podobni polovici. Tak je tudi verz: Tiho zdaj gre ob obali $\mid$ móčno šumečega morja.

Mimo klasične teorije slovenskega heksametra je Omerza pogosto uporabil žensko zarezo. Omerza se je zaradi tega opravičeval, a Ušeničnik je menil: »Po mojem mnenju se prof. Omerzu tu ni bilo treba opravičevati. Res so šestomeri z moško cezuro krepkejši, vendar ni resnično, da ženske zareze »skoraj ne čuti naše uho«, kakor je trdil Stritar in za njim Levec. Če zareza loči tudi misel od misli, so heksametri s tako žensko zarezo prav blagoglasni. V dolgih epičnih spevih bi bili sami verzi z moško cezuro celo preveč enolični in dolgočasni; uho bi se jih sčasoma naveličalo. Mislim, da prof. Omerza v tem lahko mirno hodi za mojstrom Homerjem! « Kot primer takšnega verza Ušeničnik navaja: Misli mladine so namrě | kot pena u zraku nestalne, / če pa je starček med njimi | naprej in nazaj se ozira.

Jože Debevec pa se je v svoji kritiki v Domu in svetu za razliko od Glonarja in Ušeničnika le dotaknil heksametra. Najbolj ga je motila napačna uporaba časov in nespoštovanje slovnice. V kritiki je predlagal tudi nekatere izboljšave, odločnejši začetek, ki smo ga že spoznali, ob koncu pa je ugotavljal: »Zaradi nekaterih nedostatkov nem torej zaenkrat prevod še ne ugaja popolnoma; z veseljem pa opazujemo, kako gosp. prevajalec napreduje od speva do speva; spričo priznane njegove pridnosti, natančnosti in njegovega lepočutja smo trdno uverjeni, da nam bo $v$ nekaj letih podal klasičen prevod nesmrtnega Homera. ${ }^{18}$

Poleg Iliade je Omerza prevajal še Odisejo. Žal je ta prevod v celoti ostal v rokopisu. Koliko spevov Odisejeje prevedel? Omerzov sodelavec in prijatelj Ivan Samsa je ob Omerzovi smrti v Vestniku Društva Jeglič zapisal: »Prevedel je vso Iliado, katere dvanajst spevov je izšlo v tisku, ostali in pa sedemnajst spevov Odisejeje ostalo v rokopisu. « Samsovo izjavo potrjuje tudi pola, ki jo je Omerza izpolnil leta 1922 ob nastajanju Slovenskega biografskega leksikona. Med drugimi prevodi je omenil, da je prevedel prvih šestnajst spevov Odiseje. Glede na Samsovo izjavo je zelo verjetno, da je kasneje prevedel še sedemnajsti spev.

\footnotetext{
${ }^{16}$ Glonar, 1917, str. 386.

${ }^{17}$ Ušeničnik, 1917, str. 233.

${ }^{18}$ Debevec, 1917, str. 183.

${ }^{19}$ Samsa, 1941, str. 338.
} 
Od teh šestnajstih ali sedemnajstih spevov se je ohranil le eden, štirinajsti. Hranijo ga v Arhivu Slovenije. Zapisan je na rdečkaste platnice zvezkov, v katere so dijaki pisali šolske spise pri latinščini in grščini. Ker še nisem zasledil, da bi kdo objavil ta spev, navajam kratek odlomek (verzi 29-34):

Zdaj pa nenadoma psi lajajoči zazro Odiseja;

glasno kričoč se nadenj spuste, previdni Odisevs

sede pa mirno na tla in palico vrže iz roke.

Zdaj ga sramotna bolest zadela pri lastni bi staji,

toda za njim pastir je z nógami urnimi skočil,

stekel skoz vežo takoj, ko usnje iz rok mu je padlo.

Omerzov prevod tega odlomka lahko postavimo ob bok Sovretovemu; Sovretov jezik je na tem mestu tako izumetničen, da je Omerza današnjemu bralcu celo bližji:

Zdaj uzró Odiseja nenadoma lájavci budni.

$\mathrm{Z}$ divjim bevkôtom stekó proti njemu: a zviti Odísej

modro se usede na tla in spusti gorjačo iz roke.

Tu bi na svoji pristavi domala grdó jo bil skupil,

Toda za psi priteče svinjar na vrata dvoriščna,

kar le nogé ga nesó, iz rok je padlo mu usnje. ${ }^{20}$

\section{Prevodi grških tragikov}

Prvi slovenski prevodi grških tragikov segajo v konec devetnajstega stoletja, ko sta Matija Valjavec in Rajko Perušek prevedla Ajanta in Ojdipa na Kolonu. Nekaj let kasneje, leta 1912, je Cvetko Golar prevedel še Antigono. Omerza je tem prevodom dodal še Sofoklovi tragediji Filoktet in Kralj Ojdip ter Ajshilovo trilogijo Oresteja.

Zgodovinar in umetnostni kritik Jože Kastelic je leta $1944 \mathrm{v}$ drobni knjižici Antična tragedija $v$ slovenšcini kratko opisal in ocenil tudi dotedanje prevode grških tragikov. Zanimivo je, da je vedno skušal nakazati tudi razloge, ki so vplivali na izbor tragedije. O Omerzi je tako zapisal: »Skeptični Euripides tudi pri Omerzu ni našel milosti; Sofokles je zastopan najprej s Filoktetom-verjetno zato, ker je ta drama v neposredni zvezi s trojansko vojno in torej s Homerjem, ki ga je Omerza prevajal; nato pa z Oidipom - klasično dramo grškega slovstva. Nato pa se je Omerza lotil vrhunca grške poezije in ene največjih dramatskih umetnin svetovnega slovstva - Aishilove Orestije. ${ }^{21}$

Svojo prvo tragedijo, Filokteta, je Omerza začel objavljati kmalu po zaključku študija na Dunaju leta 1913 in prihodu na Škofijsko klasično gimnazijo. V oktobrski številki Mentorja je v kratkem članku najprej opisal grško gledališče

${ }^{20}$ Homer: Odiseja. Prevedel A. Sovrè. Ljubljana, 1965.

${ }^{21}$ Kastelic, 1944, str. 5. 
in njegov razvoj, nato pa je v devetih nadaljevanjih objavil svoj prevod. Dodal mu je obširne mitološke opombe, tudi s citati iz Iliade, ki jo je tedaj prevajal.

V letih 1918 in 1919 je v Mentorju objavil prevod Kralja Ojdipa. Po mnenju Kajetana Gantarja njegov prevod odlikuje predvsem velika zvestoba do izvirnika. ${ }^{22}$ Jože Debevec pa je leta 1923 ob izidu novega, Sovretovega prevoda tragedije zapisal: "Poglavitni razloček med prevodom Franca Omerze /.../ na eni ter Sovretovim na drugi pa vidimo pri najtežjih partijah tragedije, pri liričnih zborih. /.../ Dočim se Omerza drži načela, da jih je treba prevajati v težkih, zapletenih metrih izvirnika (in baš vsled tega so v prevodu neužitni), je Sovrè storil odločilen korak in jih prevel svobodno. ${ }^{23}$ Razliko med prevodoma je Debevec duhovito enačil z razliko med težkim železniškim vlakom in letalom.

Po Filoktetu in Kralju Ojdipuje Omerza prevedel še Ajshilovo trilogijo Oresteja. Prvi in drugi del, Agamemnona in Maščevanje, je objavil v Mentorju, tretji del, Evmenide, pa je žal ostal v rokopisu, ker je Mentor prenehal izhajati. In kako se je Omerza spoprijel z zahtevnim Ajshilovim izvirnikom? Po Kasteličevem mnenju je bil Omerza vsem tem težavam vsaj toliko kos, da je prevod čitljiv in razumljiv, včasih morda celo pretresljiv. ${ }^{24}$ Jože Debevec pa je v kritiki ob uprizoritvi Oresteje v zavodu menil, da bi prevajalec moral prevajati bolj vzvišeno ter omiliti nekatere izraze, kot na primer baba, krava .... ${ }^{25}$

Za vtis o Omerzovih prevodih grških tragedij navajam zaključno zborovsko pesem iz Kralja Ojdipa (verzi 1524-1530). Odlomek je leta 1921, ko so v zavodu igrali Kralja Ojdipa, uglasbil Marij Kogoj in ga najdemo na zgoščenki Slovenski samospevi $X X$. stoletja. ${ }^{26}$

Glejte, o možje Tebanci, glejte tega Ojdipa,

ki je znal uganko slavno, bil najslavnejši je mož!

Kdo ga blagroval ni v mestu, gledal zavidljivo nanj?

Toda kák naval nesreče strášne ga zadel je zdaj!

Zadnje torej dni počakaj in nikogar ne blagruj,

ki živi pri nas na zemlji kakor človek umrljiv,

dokler ni končal življenja in trpljenja ni poznal! $!^{27}$

Štiri leta po objavi Omerzovega prevoda je Kralja Ojdipa poslovenil Anton Sovrè. Njegov prvi prevod učinkuje zelo izumetničeno in nenaravno. Kasneje je Sovrè še večkrat prevedel Kralja Ojdipa, in ti prevodi so mnogo boljši, zrelejši. Tu navajam odlomek iz prve različice.

Ózrite se, Theb rojaki, na Oidípa, ki je znal

razgonetiti slovito zagonetko, ki je kralj

vsemogočen bil, da gledal nanj zavistno je meščan,

\footnotetext{
22 Prim. Gantar, 1959, str. 86.

${ }^{23}$ Debevec, 1923, str. 60.

${ }^{24}$ Prim. Kastelic, 1944, str. 5.

${ }^{25}$ Prim. Debevec, 1920, str. 2.

${ }^{26}$ Založba kaset in plošč RTV Slovenija, 1997.

${ }^{27}$ Mentor, 1918/1919, str. 88.
} 
glejte, kák zlosreče val je zgrnil se nad njim strašán!

$\mathrm{O}$, zatorej ne blagrujte zemeljskega potnika,

ki življenja dan poslednji v sinji dalji še ima;

preden ni dospel do meje žitja svojega - brez zla. ${ }^{28}$

\section{»Vojna« prevoda}

Prva svetovna vojna je močno vplivala na delovanje Zavoda sv. Stanislava in s tem tudi gimnazije. Vojaška oblast je namreč kmalu po začetku vojne $v$ zavodu ustanovila rezervno bolnišnico za šeststo ranjencev. Pod vplivom groze prve svetovne vojne je Omerza prevedel Aristofanovo komedijo Mir in jo leta 1918 objavil $v$ Domu in svetu. V prevodu je izpustil nekatere verze, ki so se $m u$

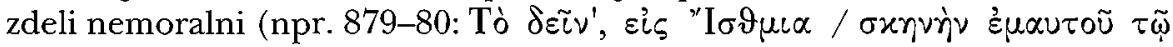

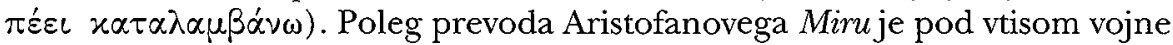
nastal tudi članek L. 431. pr. Kr. in l. 1916. po Kr. v katerem je Omerza objavil prevod iz Tukididove Peloponeške vojne (2,34-47), Periklov govor na pogrebu padlih atenskih vojakov leta 431 pred Kristusom. Zelo zanimiv je uvod k prevodu, v katerem se kaže Omerzovo nadčasovno pojmovanje antike in skoraj meditativen odnos do nje: "Ljudstvo se vrača domov. Toda glej, ne gre po isti poti, kakor je prišlo. Proti severu hiti, h koncu pokopališča. Čemu neki to? Zdaj šele zagledaš tam v kotu lesen oder. Izmed množice stopi nekdo na vzvišen prostor. Kdo je to, vprašaš, ki hoče v tako resnem trenutku govoriti pred toliko množico, da potolaži potrta srca zapuščenih vdov, obriše grenke solze ljubečim materam? « ${ }^{29} \mathrm{Ob}$ koncu članka si Omerza zaželi, da bi Perikles vstal in spet spregovoril v slovo padlim junakom, da bi razveselil matere in obrisal solze mladi ženi...

\section{Prevodi rimske poezije}

Pomemben del Omerzovega prevajalskega opusa predstavljajo tudi prevodi rimske poezije. Žal velik del teh prevodov ni bil objavljen.

Od Horacijevih od so bile objavljene le tri s poučno vsebino: Rectius vives, Licini, neque altum (2,10), Angustam amice pauperiem pati $(3,2)$ ter Divis orte bonis, optume Romulae (4,5). V celoti je prevedel tudi Horacijeve satire Qui fit, Maecenas, ut nemo, quam sibi sortem (1,1), Omnibus hoc vitium est cantoribus, inter amicos (1,3), Egressum magna me accepit Aricia Roma $(1,5)$ ter Ibam forte Via Sacra, sicut meus est mos $(1,9)$. Poleg teh štirih satir je prevedel še druge. Leta 1922 je imel - tako je sam zapisal na polo za Slovenski biografski leksikon - v rokopisu še pet Horacijevih in enajst Juvenalovih satir.

V Mentorju je objavil tudi večje število epigramov: 83 Marcialovih in 14 Katulovih. Na poli, ki jo je izpolnil za Slovenski biografski leksikon, pa je

${ }^{28}$ Sophokles, Kralj Oidipus. Prevedel A. Sovrè. Ljubljana, 1922.

${ }^{29}$ Mentor, 1915/1916, str. 119. 
zapisal, da ima v rokopisu še tristo štiriindvajset Marcialovih epigramov ter deset, dvanajst Katulovih. Vse te je leta 1920 ponudil v objavo uredniku Doma in sveta, a žal niso bili objavljeni.

\section{Prevodi cerkvenih očetov}

Omerza pa ni oral ledine samo pri prevajanju antične književnosti, ampak tudi pri prevajanju cerkvenih očetov. Prevajati jih je začel pod vplivom patristične renesanse, ki se je v Evropi začela v letih pred prvo svetovno vojno. Jeseni leta 1915 je tako v Mentorju zapisal: $» V s i$ narodi polagoma prihajajo do spoznanja, da tiči v cerkvenih pisateljih polno zlatih misli, ki so nam po večini neznane. Zato se je začel učeni svet zanimati ne le za stare klasične pisatelje grške in latinske, ampak tudi za poznejšo dobo. «30 Ker šolska lektira v škofijskih in celo v jezuitskih gimnazijah ni nikoli predvidevala, da bi dijaki brali cerkvene očete, je začel v Mentorju objavljati odlomke iz del grških cerkvenih očetov. V treh letih je tako objavil odlomke iz pisem sv. Ignacija Rimljanom in Efežanom, iz poročila o mučeništvu sv. Polikarpa, iz Didahe ter iz Barnabovega pisma. Dijaki so te odlomke s pomočjo Doklerjevega grško-slovenskega slovarja, ki je izšel istega leta, prevajali kot vajo za šolske naloge. Najboljše prevode je Omerza objavil v Mentorju.

Poleg odlomkov iz Mentorja je v zgodnjem obdobju prevedel še dve deli: Spise apostolskih očetov in Prve krščanske apologete. Slednji so ostali v rokopisu, Spisi apostolskih očetov pa so v knjižni obliki izšli šele leta 1939. Prevajalec je bil podpisan kot Franc Pavlanski Omerza; pridevek Pavlanski prihaja iz imena Frančiška Paolskega (umrl je leta 1507), ustanovitelja reda najmanjših bratov. $\mathrm{V}$ uvodu k novemu prevodu Spisov apostolskih očetov je Grorazd Kocijančič navedel razloge za nov prevod in hkrati kratko ocenil Omerzovega: »Prevod F. Omerze je bil za svoje čase odličen, vendar je bil vseeno potreben temeljite revizije. Prvi razlog zanjo je bil filološki: sodobna načela prevajanja se nekoliko razlikujejo od Omerzovih: mesta, ki jih je njegov prevod gladil, se nam danes zdijo bolj pomenljiva prav v svoji »okornosti« in nedorečenosti. /.../ Poleg tega je skoraj 60 let v jeziku precej dolga doba, tako da sem v večino stavkov moral poseči $z$ večjimi ali manjšimi popravki, kar pa je bilo prijetno delo ob imenitnih sintaktičnih rešitvah, ki jih ponuja Omerzov prevod in sem jih v veliki meri ohranil. ${ }^{31}$ Kocijančič pravi, da med prevajalci patrističnih besedil še ni naletel na tako dognano in notranje konsistentno prevajalsko poetiko, kot je Omerzova.

Med drugo svetovno vojno, leta 1942, dobro leto dni po Omerzovi smrti, je Mohorjeva družba izdala še Svetega Janeza Krizostoma izbrane spise. Omerza je prevedel prve štiri knjige, peto pa je zaradi bolezni pustil nedokončano. Njegov prevod je nato dokončal Franc Ksaver Lukman. Skupaj z Lukmanom je Omerza prevajal tudi Tertulijanove spise. Žal ti prevodi zaradi vojne in ko-

${ }^{30}$ Mentor, 1915/1916, str. 29.

31 Spisi apostolskih očetov, 1996, str. 17. 
munizma po vojni niso bili objavljeni. Danes so shranjeni v knjižnici Teološke fakultete, Miran Špelič pa je nekatere prevode jezikovno popravil in objavil na svetovnem spletu. ${ }^{32}$

Poleg grške in latinske književnosti je Franc Omerza prevajal tudi nemško, seveda v veliko manjši meri. Leta 1935 je pri Delavski založbi izšel prvi del romana Hagarin sin Paula Kellerja, naslednje leto je izšel še drugi del romana ter kratka povest Med mejaši istega avtorja. Leta 1938 pa je v Slovencu v Omerzovem prevodu kot podlistek izhajal roman Ilse von Stach Poslanci iz Voghere.

\section{Neobjavljeni prevodi}

Kot smo videli že doslej, je mnogo Omerzovih prevodov ostalo neobjavljenih. Na raznih mestih pa sem našel še nekatere druge zapise, ki govorijo o neobjavljenih prevodih.

Omerzov sodelavec Franc Glinšek je tako v Vestniku Društva Jeglič ${ }^{33}$ zapisal, da je Omerza poleg Miru poslovenil še Aristofanovo komedijo Oblaki, a da je ostala v rokopisu. Cez nekaj mesecev je ob Omerzovi smrti Ivan Samsa prav tako v Vestniku Društva Jeglič pisal: $» V$ rokopisu so se nam ohranili prevodi Platonovih dialogov Gorgias, Apologija, Kriton, Fajdon, Eutifron, Harmides. Prevedel je vso Iliado, katere dvanajst spevov je izšlo v tisku, ostali in pa sedemnajst spevov Odiseje je ostalo v rokopisu. « ${ }^{34}$ Zelo zanimiv je tudi govor psihologa dr. Leona Žlebnika, nekdanjega Omerzovega dijaka, ob trideseti obletnici mature. ${ }^{35}$ Ko je govoril o Omerzi, je naštel tudi več porumenelih listov, ki so ostali neobjavljeni: Galska vojna, O slavnih možeh, Cicerov govor proti Katilini in o Sekstu Rosciu ter Senekovo razpravo O srečnem življenju, od že omenjenih pa Iliado in Odisejo ter Platonovega Fajdona in Apologijo.

Od teh neobjavljenih prevodov se je, kot smo že omenili, ohranil le štirinajsti spev Odiseje. Ostali prevodi so bili zelo verjetno uničeni med drugo svetovno vojno. Po Omerzovi smrti so namreč njegove knjige in rokopisni prevodi pristali v eni od knjižnic v Zavodu sv. Stanislava. Po začetku druge svetovne vojne na Slovenskem aprila leta 1941 je del zavoda zasedla italijanska vojska, kmalu nato pa nemška. Po prihodu nemške vojske so morali vsi profesorji in dijaki v nekaj urah zapustiti zavod; s sabo so lahko vzeli le svojo obleko in nekaj knjig. V vsej tej zmedi najverjetneje ni nihče s sabo vzel Omerzovih rokopisnih prevodov, saj so bile takrat v zavodu tudi veliko dragocenejše knjige, na primer Dalmatinova Biblija. Večino knjig in ostalega gradiva, ki ga niso sežgali, so Nemci prepeljali v Kranj, kjer so hoteli ustanoviti nekakšno osrednjo knjižnico za vso Gorenjsko. Po koncu vojne so bile vse te knjige in drugo gradivo odpeljano v Ljubljano

32 Spisi Pričevanje duše, Mučencem ter $O$ krstu so objavljeni na naslovu http://www2.ames. si/ supmspel/patres/tertulijan. Kot prevajalec teh spisov je naveden samo Lukman, verjetno zato, ker je napisal opombe.

${ }^{33}$ Prim. Glinšek, 1940a, str. 314.

${ }^{34}$ Samsa, 1941, str. 338.

${ }^{85}$ Prim. Štrubelj, 1996, str. 204. 
in shranjeno v Alojzijevišču, kasneje pa razdeljeno med Semeniško knjižnico, Teološko fakulteto, Filozofsko fakulteto in tudi Malo semenišče v Vipavi. Nekje na tem »potovanju« so se izgubili tudi Omerzovi prevodi.

\section{Uprizoritev Oresteje in Kralja Ojdipa}

Profesorsko in prevajalsko delo je Omerza uspešno dopolnjeval tudi s sodelovanjem pri dramskem krožku, ki je deloval v okviru Palestre, dijaške organizacije na Škofijski klasični gimnaziji. Pod Omerzovim vodstvom so tako junija leta 1920 dijaki uprizorili Ajshilovo trilogijo Oresteja. To je bila ena prvih uprizoritev antične drame v slovenščini, pred tem so le leta 1912 v Slovenskem narodnem gledališču igrali Antigonov prevodu Cvetka Golarja. Ker je celotna uprizoritev Oresteje trajala skoraj šest ur, so jo uprizorili v dveh delih: 24. junija Agamemnona $\mathrm{z}$ uvodno pevsko točko, Pindarjevo odo Khryséa phórminx, ki jo je na klavirju igral osmošolec Matija Tomc, 27. junija pa sta sledila še Maščevanje in Evmenide.

O predstavi je izšlo le poročilo v Slovencu, ki ga je napisal Jože Debevec. Omerzo je primerjal kar s samim Ajshilom: »Kakor je starodavnik Ajshilos (umrl 1. 456. pr. Kr.) trilogijo sam spisal, zborom sam speve zložil, zboraše in igralce sam vežbal in končno sam prvo vlogo prevzel in igral - za naše pojme pač orjaško delo! - podobno je bil v našem slučaju prevajalec in vežbalec (didaskalos) isti mož - marljivi, po svojem prevodu Iliade in drugih klasičnih del dobroznani šentviški profesor Fr. Omerza. $\aleph^{36}$ Kot ljubitelj antike se je Omerza trudil, da je bila uprizoritev kar najbolj podobna avtentični. Tudi zato, ker je bila gimnazija fantovska, so tudi ženske vloge igrali fantje. Igrali so na prostem, vendar ne vse tri tragedije zapored, kakor nekoč v Atenah. Fotografije s predstave kažejo, da niso nosili mask kot $\mathrm{v}$ antiki in zato gledalci v primerjavi z antično publiko niso bili prikrajšani za obrazno mimiko. Razkošne kostume, ki so jih nosili, je zavodu brezplačno posodila uprava narodnega gledališča.

Po uspehu Oresteje se je Omerza z dramskim krožkom lotil še uprizoritve Kralja Ojdipa. Uprizorili so ga dvakrat, 16. in 19. junija 1921. Omerza je k uprizoritvi te tragedije pritegnil skladatelja Marija Kogoja, ki je uglasbil vseh šest zborskih pesmi. Izvajali so jih ob spremljavi klavirja, violine in flavte. Pred predstavo je zbor - tako kot pred Orestejo - zapel odo Khryséa phórminx. V Slovencu je Franc Kimovec objavil kritiko Kogojevih skladb, posebej je presenetljiv naslednji odlomek: "Le čudimo [se], kako je bilo mogoče izvršiti vse to obsežno delo: kompozicijo, učenje in $v$ celoti dobro izvajanje $v$ štirinajstih dneh. Brez posebnega truda in vztrajnega napora bi bilo to popolnoma nemogoče. ${ }^{37}$

Žal pa o predstavi obstaja le en sam zapis. Tako kot o Oresteji ga je tudi o Kralju Ojdipu napisal Jože Debevec. Za vtis navajam naslednji odlomek: »In kaj naj rečem o igravcih? Najprej to, da so izborno znali vsak svojo vlogo: šepetavca nismo čuli niti enkrat. Dobro napamet znati - to je že polovica uspeha.

${ }^{36}$ Debevec, 1920, str. 1.

${ }^{37}$ Kimovec, 1921, str. 3. 
Ojdipus (Mikavčič VI. r.), ki je nosil glavno težo dneva, je bil srečno izbran: dobro se je videlo, kako se ob vsakem koraku, ki ga hoče storiti naprej k sreči, zdrzne in prestrašen obstane; in da je v končnem prizoru, O. - sam si oči iztaknivši - slovo jemlje od naroda, od obeh hčerk, toliko pretresljive tragike, smo šele ob tej priliki prav videli, dasi smo dramo že opetovano čitali; prizor je bil mojstrsko izveden. Glede uloge kraljice Jokaste pa le-to: kdor ve, da so pri starih Grkih vse uloge igrali moški, je bil z igro popolnoma zadovoljen, uvažujé posebne težkoče baš te naloge; enemu delu občinstva je pa seveda za par hipov iluzija pošla.« ${ }^{38}$

$\mathrm{Z}$ uprizoritvijo Oresteje in Kralja Ojdipa je dal Omerza bistven prispevek k slovenski kulturi. Gledališka zgodovina in kritika doslej še nista ovrednotili dejstva, da sta bili zahtevni predstavi Oresteje in Kralja Ojdipa na Slovenskem prvič uprizorjeni na diletantskem odru, vendar, če sodimo po dveh kritikah iz tistega časa, na zavidljivi kvalitetni ravni.

Franc Omerza je slovensko kulturo zaznamoval na številnih področjih: kot plodovit prevajalec antične književnosti in cerkvenih očetov, kot profesor klasične filologije na Škofijski klasični gimnaziji, kot mentor dramskega krožka.

Čeprav je prvi prevedel v slovenščino številna pomembna antična dela, širšemu občinstvu ni bil nikoli posebej znan. Zaradi njegove mladosti, hitrega razvoja slovenščine in pretirane zvestobe izvirniku so njegovi prevodi hitro zastarali in zato nikoli niso bili zgled poznejšim prevajalcem. Kljub temu si Franc Omerza kot najpomembnejši prevajalec antične književnosti z začetka dvajsetega stoletja zasluži večjo pozornost.

\section{DODATEK}

\section{Bibliografija Omerzovih objavljenih prevodov}

\section{Knjižne izdaje}

- Homer: Iliada. I.-VI. spev. Ljubljana, 1916.

- Spisi apostolskih očetov. Celje, 1939.

- Svetega Janeza Krizostoma izbrani spisi. Celje, 1942.

- Spisi apostolskih očetov (prevedli Fran Omerza, Anton Strle in Gorazd Kocijančič). Celje, 1996.

\section{Objave v revijah}

- Ajshil: Agamemnon. Mentor 11 (1918/1919), str. 144-150, str. 163-168. Mentor 12 (1921/1922), str. 6-10, str. 38-42, str. 73-77, str. 99-109, str. 133-143.

- Ajshil: Maščevanje. Mentor 13 (1922/1923), str. 8-13, str. 44-52, str. 74-82, str. 115-126.

${ }^{38}$ Debevec, 1921, str. 2. 
- Aristofan: Mir. Dom in svet 31 (1918), str. 96-98, str. 157-161, str. 216234.

- Homer: Iliada. Prvi spev: Mentor 6 (1913/1914), str. 187-189, str. 200-211. Drugi spev. Mentor 7 (1914/1915), str. 13-20, str. 56-61, str. 90-92, str. 112-113, str. 126-128. Tretji spev. Mentor 7 (1914/1915), str. 128-130, str. 150-156. Četrti spev. Mentor 7 (1914/1915), str. 182-193. Peti spev. Mentor $8(1915 / 1916)$, str. $8-13$, str. 65-71, str. 123-128. Šesti spev. Mentor 8 (1915/1916), str. 182-185, str. 230-232. Mentor 9 (1916/1917), str. 12-17. Sedmi spev. Mentor 9 (1916/1917), str. 50-54, str. 83-87. Osmi spev. Mentor 9 (1916/1917), str. 132-135, str. 160-164, str. 198-200. Deveti spev. Mentor 9 (1916/1917), str. 236-241. Mentor 10 (1917/1918), str. 12-15, str. 52-55. Deseti spev. Mentor 10 (1917/1918), str. 86-91, str. 126-131. Enajsti spev. Mentor 10 (1917/1918), str. 174-177, str. 217 221. Mentor 11 (1918/1919), str. 16-19, str. 59-63. Dvanajsti spev. Mentor 11 (1918/1919), str. 100-106, str. 122-124. Trinajsti spev. Mentor 12 (1921/1922), str. 22-26, str. 49-52, str. 83-87, str. 156-159. Štirinajsti spev. Mentor 13 (1921/1922), str. 159-164.

- Horacij: Angustam amice pauperiem pati (3,2). Mentor 8 (1915/1916), str. 29

- Horacij: Divis orte bonis, optume Romulae (4, 5). Mentor 7 (1914/1915), str. 35.

- Horacij: Egressum magna me accepit Aricia Roma (1, 5). Dom in svet 30 (1917), str. 285-286.

- Horacij: Ibam forte Via Sacra, sicut meus est mos (1, 9). Dom in svet 31 (1918), str. 42.

- Horacij: Qui fit, Maecenas, ut nemo, quam sibi $\operatorname{sortem}(1,1)$. Dom in svet 30 (1917), str. 236-237.

- Horacij: Omnibus hoc vitium est cantoribus, inter amicos $(1,3)$. Dom in svet 30 (1917), str. 287-288.

- Horacij: Rectius vives, Licini, neque altum (2, 10). Mentor 7 (1914/1915), str. 97.

- Katul: Epigrami. Mentor 9 (1916/1917), str. 146-150.

- Marcial: Epigrami. Mentor 9 (1916/1917), str. 57-63, str. 92-96. Mentor 11 (1918/1919), str. 30, str. 70, str. 129, str. 182.

- Sofokles: Filoktet. Mentor 6 (1913/1914), str. 1-4, str. 24-28, str. 45-47, str. 66-72, str. 103-107, str. 136-139, str. 165-167, str. 178-180.

- Sofokles: Kralj Ojdip. Mentor 10 (1917/1918), str. 117-123, str. 161-169, str. 197-210. Mentor 11 (1918/1919), str. 1-9, str. 42-48, str. 82-88.

- Tukidid: Peloponeška vojna (II. 34-47). Mentor 8 (1915/1916), str. 118-123.

\section{LITERATURA}

Debevec, J.: Homerjeva Iliada. Dom in svet 30 (1917), str. 182-183.

Debevec, J.: Kralj Ojdipus prvič med Slovenci. Slovenec, 22. 6. 1921, str. 2. 
Debevec, J.: Sophokles: Kralj Ojdipus. Dom in svet 36 (1923), str. 59-60.

Debevec, J.: Starogrška drama v zavodu sv. Stanislava. Slovenec, 3. 7. 1920, str. $1-2$.

Gantar, K.: Kralj Oidipus v slovenski literaturi. V Sofokles: Kralj Oidipus. Ljubljana, 1959.

Glinšek, F.: Dragemu učitelju prof. Omerzi. Vestnik Društva Jeglič (1940a), str. 313-315.

Glinšek, F.: Prof. Fr. Omerzu v spomin! Slovenec, 19. 12. 1940b, str. 8.

Glonar, J. A.: Fr. Omerza: Homerjeva Iliada. Ljubljanski zvon 36 (1917), str. 386-389.

Grivec, F.: Sv. Janez Zlatoust. Doneski v proslavo 1500-letnice njegove smrti. Maribor, 1908.

Kastelic, J.: Antična tragedija v slovenščni. Ljubljana, 1944.

Kimovec, F. Zbori k Sofoklejevemu kralju Ojdipu. Slovenec, 22. 6. 1921, str. 2-3.

Koritnik, A.: Ob srebrnem jubileju škofijskega Zavoda sv. Stanislava in škofijske gimnazije. St. Vid nad Ljubljano, 1930.

Kronika. Osebne vesti. Vestnik Društva Jeglič (1939), str. 269-270.

Kronika. Zadnji dnevi in zadnja pot profesorja Omerze. Vestnik Društva Jeglič (1941), str. 351-352.

Moder, J.: Starogrška epika, lirika in dramatika pri Slovencih. V: Zgodovina grške knjižeunosti. Ljubljana, 1966.

Omerza, F.: Rimska satira. Dom in svet 30 (1917), str. 234-237.

Samsa, I.: Manom prof. Fr. Omerza. Vestnik Društva Jeglič (1941), str. 337-340. Slovenski biografski leksikon. Druga knjiga: maas-qualle. Ljubljana, 1933-1952.

Štrubelj, L.: Š vedno živo drevo. Zavod sv. Stanislava skozi desetletja. Ljubljana, 1996

Ušeničnik, A.: Slovenska Iliada. Čas 10 (1917), str. 230-235.

\section{A Portrait of Franc Omerza}

\section{Summary}

Franc Omerza (1885-1940) was a high-school teacher, translator, and the mentor of a drama club. After graduating in theology at Ljubljana, he was ordained in 1908. He studied classical philology in Vienna and started teaching Latin and Greek at the Ljubljana Diocesan Classical Gymnasium in 1913. He is important primarily as a translator of ancient literature (the Iliad and a part of the Odyssey, Sophocles' Philoctetes and Oedipus the King, Aeschylus' Oresteia etc.) and the Greek Fathers of the Church. The translations were published in the periodicals Dom in svet and Mentor, the latter edited for a while by Omerza himself. However, he only published three books: the first half of Homer's Iliad and two volumes of selections from the Fathers of the Church. As the mentor of the school drama club, he directed several plays, the most important being the first Slovene performances of Aeschylus' Oresteia and Sophocles' Oedipus the King.

It can be assumed from Omerza's correspondence and other contemporary 
sources that he translated the complete text of Homer's Iliad, although the translation is now lost. This fact has hitherto escaped the historical researches into Slovene literary translation. 